กORTH CLIO ISTAกB 2018;5(1):41-46 doi: $10.14744 /$ nci.2017.50480

\title{
Evaluation of patients with gastric polyps
}

\author{
Sehmus Olmez, ${ }^{1}$ Suleyman Sayar, ${ }^{2}$ Bunyamin Saritas, ${ }^{3}$ Ayla Yildiz Savas, ${ }^{4}$ Ufuk Avcioglu, ${ }^{5}$ Ilyas Tenlik, ${ }^{6}$ \\ Ersan Ozaslan, ${ }^{7}$ Hasan Tankut Koseoglu, ${ }^{7}$ Emin Altiparmak ${ }^{7}$ \\ ${ }^{1}$ Department of Gastroenterology, Adana Numune Training and Research Hospital, Adana, Turkey \\ 2Deparment of Gastroenterology, Umraniye Training and Research Hospital, Istanbul, Turkey \\ ${ }^{3}$ Department of Gastroenterology, Mersin University Faculty of Medicine, Mersin, Turkey \\ ${ }^{4}$ Department of Gastroenterology, Balıkesir University Faculty of Medicine, Balikesir, Turkey \\ ${ }^{5}$ Department of Gastroenterology, Ozel Koru Hospital, Ankara, Turkey \\ ${ }^{6}$ Department of Gastroenterology, Turkiye Yuksek Ihtisas Training and Research Hospital, Ankara, Turkey \\ ${ }^{7}$ Department of Gastroenterology, Ankara Numune Training and Research Hospital, Ankara, Turkey
}

\begin{abstract}
OBJECTIVE: The incidence of gastric polyps (GPs) greatly differs according to study populations and was found to be $0.33 \%-6.7 \%$ in various studies. The majority of GPs are composed of hyperplastic polyps (HPs), fundic gland polyps (FGPs), and adenomatous polyps (APs). Although APs have a high risk of malignant potential, sporadic FGPs have no malignant potential. Conversely, HPs have a low risk of malignant potential. It is not sufficient to perform a biopsy to identify the polyp type and the presence of dysplasia; thus, some polyps may require multiple biopsies or total excision.

METHODS: This retrospective study included patients with GPs or polypoid lesions found on esophagogastroscopy with polyp or malignant histology on biopsy at Ankara Numune Training and Research Hospital Endoscopy Unit between 2005 and 2011.

RESULTS: In a series of 56.300 upper endoscopies, 192 patients (0.34\%) were found to have GPs. Among the patients, $51(26.6 \%)$ were men and 151 (73.4\%) were women. The average age of the patients was $61.9 \pm 13.3$ (14-90) years. The frequency of HPs, APs, and FGPs were $88 \%, 2.6 \%$, and $1.6 \%$, respectively. The size of the polyps was $\leq 1 \mathrm{~cm}$ in 137 (70\%) patients. One polyp was determined in 141 (73.4\%) patients. The most common localizations of polyps were the antrum and corpus. Endoscopic snare polypectomy was performed in 64 patients. One bleeding episode was observed, which required endoscopic treatment after ESP.
\end{abstract}

CONCLUSION: In our study, the GP frequency was low $(0.34 \%)$, whereas the frequency of HP maybe high due to the high frequency of Helicobacter pylori (HPy) infection in our country. The frequency of FGP is probably low due to the high frequency of HPy infection and the short-term use of proton-pump inhibitors.

Keywords: Endoscopic polypectomy; hyperplastic polyp; gastric polyp.

$\mathrm{P}$ olyps are usually asymptomatic and $>90 \%$ of polyps were coincidentally detected on esophagogastroduodenoscopy performed for other reasons. Large polyps may cause bleeding, anemia, abdominal pain, or may lead to obstruction rarely due to its localization [1].

A definite diagnosis of polyps should be made by histological examination [2]. The frequency of gastric polyps (GPs) and types of polyps greatly varies depending on the population in which the study is conducted. The frequency of polyps is $0.6 \%-6 \%[3,4]$. The great majority of polyps detected in the stomach are hyperplastic polyps (HPs), fundic gland polyps (FGPs), and adenomatous polyps (APs) [5]. HPs are the most common in populations in which Helicobacter pylori ( $\mathrm{HPy}$ )

Received: December 18, 2016 Accepted: July 31, 2017 Online: January 10, 2018

Correspondence: Dr. Sehmus Olmez. Adana Numune Egitim ve Arastirma Hastanesi, Gastroenteroloji Bolumu, Adana, Turkey.

Tel: +90 5356181980 e-mail: drsehmusolmez@gmail.com

(c) Copyright 2018 by Istanbul Provincial Directorate of Health - Available online at www.northclinist.com 
infection is common [6]. In countries where HPy infection is low, FGP is more common [3]. In addition, the frequency of FGP increases with the use of long-term proton-pump inhibitors (PPIs) [7].

The importance of GPs arises from the fact that some GPs have malignant potential or are associated with some hereditary syndromes [1]. Although GPs are seen in some congenital diseases such as familial adenomatous polyposis, juvenile polyposis, and PeutzJeghers syndrome, the great majority are coincidentally detected [8]. There is an increased risk of cancer in polyps other than FGPs and inflammatory fibrinoid polyp (IFPs). While the risk of malignancy is low in HPs, malignant transformation is seen more frequently in APs. Due to their malignant potential and symptomatic nature, the treatment of GPs is complete removal of the polyps by endoscopic or surgical excision [1].

In this study, we aimed to evaluate the demographic, clinical, endoscopic, and histological data of patients with polyps or polyp-like lesion or malignancy in their histological examination. In addition, we aimed to evaluate the diagnostic procedures, treatment modalities which were applied to treated patients, complications of these treatments, and relationship between age and polyp's size and number.

\section{MATERIALS AND METHODS}

At the Ankara Numune Training and Research Hospital Gastroenterology Clinic Endoscopy Unit, we retrospectively screened the findings in 56.300 consecutive esophagogastroduodenoscopy (EGD) procedures that were performed for various reasons between September 2005 and December 2011. Permission was obtained from the local ethics committee for the study.

Patients in whom GPs or polyp-like lesions were found on EGD and polyps or malignant histology on biopsy were included in the study. Patients without polyps on biopsy, previously taken for the study and inaccessible to their pathology records, were excluded from the study. Patients were screened in detail. We evaluated the age, sex, endoscopic indications, endoscopic findings, GP count, size and localization, diagnostic methods used for histology, and complications of endoscopic treatment if it was performed. The relationship between age and polyp size and count was also evaluated.

The endoscope used was a Fujinon EG 530 WR video gastroscope (Fujinon, Omiya, Japan; diameter $9.4 \mathrm{~mm}$, working channel $2.8 \mathrm{~mm}$ ). The polyp size was estimated by comparing it with the opening size of the biopsy forceps. In patients with multiple polyps, the diameter of the polyp was calculated by measuring the diameter of the largest polyp.

\section{Statistical Analysis}

SPSS for Windows 18 package program (SPSS Inc, Chicago, Illinois) was used to analyze data. Descriptive statistics were used to describe continuous variables. The $x^{2}$ (Fisher's exact) test was used for categorical variables and expressed as observation counts (and percentages). Statistical significance was accepted when a twosided p-value was $<0.05$. The Kolmogorov-Smirnov test was used to analyze categorical data that fit normal distribution whereas Spearman correlation was used if the distribution of variables was not normal.

\section{RESULTS}

A total of 56.300 patients who underwent EGD in our endoscopy unit was included. GPs were found in 192 patients. We found the incidence of GP as $0.34 \%$.

TABLE1. Demographics data and clinical characteristics of patients

Patients $\mathrm{n}(\%)$

Sex

Male

$51(26.6)$

Female

$141(73.4)$

Age (years)

Male

$65.9 \pm 11.6(35-90)$

Female

$60.5 \pm 13.7(14-88)$

Total patients

$61.9 \pm 13.3(14-90)$

Symptom

Dyspepsia

60 (31.3)

Anemia

44 (22.9)

Abdominal pain

39 (20.3)

Other

49 (25.5)

Polyp size (Mean \pm SD) (mm)

Distribution of polyp size $(\mathrm{mm})$

$<6$

$11.0 \pm 8.4(3-75)$

6-10

51 (26.6)

86 (44.8)

43 (22.4)

$>20$

$12(6.3)$ 


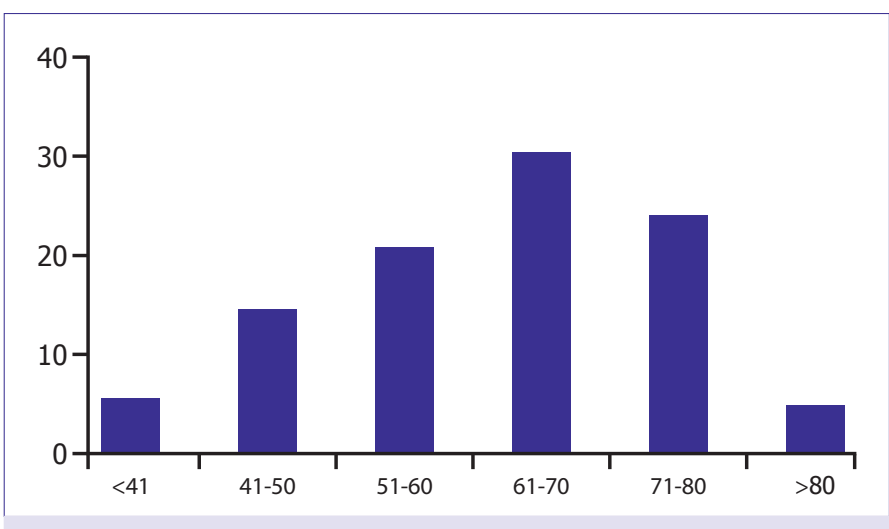

FIGURE 1. The age distribution of patients with gastric polyps.

Patient characteristics are shown in Table 1. The age distribution of patients was evaluated. Of the patients, $5.7 \%$ were under the age of 41 years, $14.6 \%$ were $41-$ 50 years, $20.8 \%$ were $51-60$ years, $30.2 \%$ were $61-70$ years, $24 \%$ were $71-80$ years, and $4.7 \%$ were $>80$ years. The age distribution of the patients is summarized in Figure 1. The average polyp diameter of the patients was $11.0 \pm 8.4$ (range: $3-75) \mathrm{mm}$. The diameters of the polyps were $\leq 5 \mathrm{~mm}$ in $51(26.6 \%)$ patients, $6-10 \mathrm{~mm}$ in $86(44.8 \%)$ patients, $11-20 \mathrm{~mm}$ in $43(22.4 \%) \mathrm{pa}$ tients, and $>20 \mathrm{~mm}$ in $12(6.3 \%)$ patients. There was no statistically significant correlation between age and polyp size $(\mathrm{p}>0.05)$. Endoscopically, one polyp was found in $73.4 \%$ of the study patients. More than one polyp was found in $26.6 \%$ of the patients. There was no relation between age and polyp count $(\mathrm{p}>0.05)$.

Histopathologic diagnosis of polyps was made with only biopsy in $52(27.1 \%)$ patients, with polypec-

TABLE 2. The distribution of histopathologic types of gastric polyps

\begin{tabular}{lcc} 
& $\begin{array}{c}\mathrm{n} \\
\text { (total=192) }\end{array}$ & $\%$ \\
\hline Hyperplastic polyp & 169 & 88 \\
Foveolar hyperplasia & 9 & 4.7 \\
Fundic gland polyp & 3 & 1.6 \\
Adenomatous polyp & 5 & 2.6 \\
Adenomatous and hyperplastic polyp & 1 & 0.5 \\
Inflammatory fibroid polyp & 1 & 0.5 \\
Fibrotic polyp & 1 & 0.5 \\
Adenocarcinoma & 2 & 1 \\
Carcinoid Tumor & 1 & 0.5 \\
\hline
\end{tabular}

tomy using biopsy forceps in 75 (39.1\%) patients, with polypectomy with snare in $64(33.3 \%)$ patients, and with enucleation via surgical procedure in one patient who could not be diagnosed with endoscopic biopsy. Histologically, the polyp diagnosed with enucleation was reported to be an IFP. Foveolar hyperplasia was found in nine cases (4.7\%). The histological distribution of the patients is summarized in Table 2. Only two cases (1\%) with GP were diagnosed with adenocarcinoma. The most common localizations of GPs were the antrum $(35.9 \%)$, followed by the corpus $(25.5 \%)$ and cardia $(15.1 \%)$. Polypectomy was performed in 75 patients $(39.1 \%)$ using biopsy forceps. No complications were seen in 74 patients who underwent polypectomy using biopsy forceps; only one patient experienced bleeding in the form of leakage during polypectomy, and hemorrhage was controlled with sclerotherapy.

Polypectomy with snare was performed in 64 patients $(33.3 \%)$. Polypectomy with snare was performed alone or in combination with other sclerotherapy, endoclip, or endoloop treatments. The distribution of different methods of polypectomy with snare is given in Table 3. In patients who underwent polypectomy with snare, the diameter of the polyp was $16.0 \pm 10.5$ (3-75) $\mathrm{mm}$. Complications related to polypectomy with snare were not seen in 59 (92\%) patients; bleeding was observed in four patients during polypectomy with snare. Bleeding spontaneously stopped in two patients during endoscopic polypectomy, and sclerotherapy was applied to two patients. In one patient, bleeding was observed at the base of the polyp, with hematemesis occurring 4 hours after the polypectomy with snare. Bleeding was controlled by sclerotherapy and blood transfusion was not required.

\begin{tabular}{lcc}
\hline TABLE 3. The distribution of snare polypectomy & \\
& Patients no & $\%$ \\
\hline Polypectomy with snare (PS) & 37 & 57.8 \\
PS + sclerotherapy & 21 & 32.8 \\
PS + endoloop & 3 & 4.7 \\
PS + sclerotherapy + endoloop & 2 & 3.1 \\
PS + sclerotherapy + endoclip & 1 & 1.6 \\
Total & 64 & 100 \\
\hline
\end{tabular}

PS: Polypectomy with snare 


\section{DISCUSSION}

In our study, we found that the most common symptoms in patients with GPs were dyspepsia, anemia, and abdominal pain. We also found that GPs were localized mostly in the antrum, and the most common histopathologic type was an HP.

Carmack et al. found the incidence of GP as $6.35 \%$ in 121.564 EGD operations. The most frequent polyp type was FGPs, which accounted for $77 \%$ of all polyps, whereas HPs and FHPs were $17 \%$ of all polyps. The $16 \%$ of lesions defined as polyps did not have histopathological polyp or malignant histology. They related high frequency of FGP with long-term PPI use and low frequency of HPy infection [3]. Elhanafi et al. reported that the most frequent polyp type was HP in 7,090 endoscopic procedures. They concluded that it might be caused by increased HPy infection [9]. However, Macenlle-Garcia et al, reported that GP was found in 18 patients $(0.33 \%)$ and the most frequent type was HP in 5.314 EGD procedures [10]. In a study performed by Roseau et al., GP was found in 191 (1.3\%) patients in 13.000 EGD procedures. Histology of the polyps was $\mathrm{HP}$ in 48 patients, FGP in 17 patients, and AP in 6 patients, whereas the histology of 118 patients (61.8\%) was either gastritis or normal histology [11]. In 157,902 endoscopic procedures performed by Fann et al., the incidence of polyps was found to be $2.56 \%$ and the most frequent type was FGP [12].

In our study, the most frequent type of polyp was HP. HPy infection frequency in our country is $82 \%$ [13]. In countries where the HPy frequency is high as in our country, the most frequent polyps are HPs [14]. In a study performed by García-Alonso et al., polypoid lesions were found in 269 patients (4.2\%) in 6.307 EGD procedures. The mean age of the patients was 65 years, and the proportion of the women was $61 \%$. Histology of polyps were $50.9 \% \mathrm{HP}, 7.4 \% \mathrm{FGP}$, and 3\% AP. Also, the incidence of adenocarcinoma was $1.9 \%$. Histopathologic diagnosis was normal mucosa in $29.7 \%$ of patients who had polyp in EGD [8]. Morais et al. reported GPs in 153 patients $(0.59 \%)$ in 26,000 endoscopic procedures. Of these patients, $41.2 \%$ were females and the mean age of the patients was 64 years. The frequency of polyps was $\mathrm{HP}$ in $71.3 \%$, FGP in $16.3 \%$, and AP in $12.4 \%$. Adenocarcinoma was found in one patient with HP and one patient with AP [4]. Molaei et al. reported the frequency of GP as $69.2 \%$ for HP, $6.6 \%$ for FGP, and $4.7 \%$ for AP. The mean age of the patients was 49 years and $73 \%$ were males. The size of the polyps was $<10 \mathrm{~mm}$ in $87 \%$ of the cases [14]. In a study performed by Fann et al., the mean age was 54.7 years, $63 \%$ of patients were females, and $37 \%$ of patients were males [12]. In our study, approximately $80 \%$ of the patients who were diagnosed with GPs were $>50$ years. There was no relation between age and polyp size and count. HPs and APs usually appear in older individuals [8]. The incidence of GPs was $0.59 \%-3.4 \%$ in previous studies in our country [6]. In our study, the incidence of GP was $0.34 \%$, which was lower than that in most of the other studies. The reasons for this may be due to the exclusion of patients with benign pathology or inappropriate sampling of polyps. There are few studies on GP in our country. In a study performed by Gencosmanoglu et al,, the GP incidence was $3.4 \%$, and $46 \%$ of polyps were found to be HPs, $18 \%$ were found to be FHPs and $14 \%$ were found to be FGPs. The mean age of the patients was 51 years and the proportion of women was $58 \%$. Polyp size was found to be $<5 \mathrm{~mm}$ in $58 \%$ of the patients [6]. In a study performed by Karaman et al., GP was found in 69 (0.59\%) patients in 11.598 EGD procedures. While $69 \%$ of all polyps were HPs, $10 \%$ were FGPs [15]. In the study performed by Buyukasik et al., HPs were found in $66.7 \%$ of 55.987 EGD procedures [16]. The incidence of GP was $2.22 \%$ and the highest frequency of HP was found as $36.2 \%$ in a study performed by Vatansever et al [17]. In our study, the most common polyps were HPs. However, the frequency of HP was higher than that in previous studies. In addition, the FGP frequency was significantly lower than that in other studies. However, GP was found in $66(1.95 \%)$ patients in 3.375 EGD procedures in a study performed by Demiryilmaz et al.[18] A total of 88 gastric polypoid lesions was detected in these patients. Histopathological examination of polyps revealed $80.7 \%$ as HPs, $17 \%$ as inflammatory polyps, and $2.3 \%$ as APs. No FGP was detected in this study [18].

FGP was the most frequent polyp in some studies [3-7]. The frequency of these polyps has increased due to the decrease in the frequency of HPy infection and increased use of PPIs [3]. Graham first described the development of FGP in three patients treated with omeprazole in 1992 [19]. After this definition, increased FGP frequency with the use of PPI has been shown in many studies $[20,21]$. The existence of such a relationship causes anxiety in both physicians and patients who need long-term PPI use. In a study performed by Jalving et al., there was no increase in the frequency of FGP in patients using PPI for $<1$ year. However, long-term PPI 
use was found to increase the risk of developing FGP 4-fold. However, there was no increase in the risk of dysplasia. When subgroup analysis was performed, the risk of developing FGP was observed increased significantly in patients with PPI use for more than 5 years. The increased risk of developing FGP due to long-term PPI use was not different between patients using omeprazole and those using other PPIs [7]. However, increased FGP frequency with PPI use has not been observed in some studies [22]. A total of 30,347 $\mathrm{HPy}$-negative patients were evaluated and FGP frequency was found to be similar to that in 28.096 patients who do not use PPI and 2251 patients who use PPI, and there was no increased risk of polyps in PPI users [22]. This may be due to shortterm PPI use [7]. In a study performed by Choudhry et al., patients using PPI had the highest risk of developing FGPs after a mean of 37 months [23]. Hongo et al. investigated the development of FGPs and HPs in patients with prolonged PPI use in a prospective study. Longterm PPI use has been associated with increased FGP frequency in HPy-negative patients. The formation of these polyps was not associated with hypergastrinemia. However, HP development was associated with $\mathrm{HPy}$ positivity and hypergastrinemia [24]. In our study, FGPs were found in three patients. The association of FGPs with $\mathrm{HPy}$ is known. HPy infection reduces FGP formation. These polyps are common in $\mathrm{HPy}$-negative patients [25]. This low incidence may be related to the high frequency of HPy infection in our country. However, even in countries with high HPy infection rate, the FGP frequency may be high [14], These polyps have never been observed in some studies [9]. The frequency of FGP has been associated with long-term PPI use. No increased risk for short-term use was observed [7, 14, 18]. The most common cause of EGD procedures in our patients was dyspeptic complaints. FGP frequency, which is very low in our patients, is probably due to the short duration of our patients' use of PPI therapy. Moreover, since these polyps are quite small, they may be missed during EGD operations or because they may be ignored due to their partially indistinguishability because of their endoscopic appearance.

In our study, FHPs were found in nine patients (4.7\%). These lesions are thought to be HP precursors. It is not known how often these lesions will turn into HP. The lesions may be stable or may grow or shrink [26]. However, whether they are HP precursors or not is still being debated. Stolte et al. showed that the basic structures and cytological criteria of FHPs and HPs can easily be distinguished in biopsy materials taken by endoscopic forceps. These lesions are not the result of HP precursors [27]. FHPs are highly common lesions in studies $[6,14]$. In our study, APs were detected in five patients. APs constitute $\leq 10 \%$ of GPs [5]. These polyps are more common in communities where stomach cancers are common and have high malignant potential [5]. Malignant potential of AP is $6.8 \%-55.3 \%$ [28]. The size of the lesion, high-grade dysplasia, and presence of intestinal epithelium are risk factors for malignancy development [5]. Even adenomas with low-grade dysplasia in the long-term follow-up have been shown to have a malignant potential. For this reason, excision of these lesions is recommended [29]. In addition, IFP was detected in one patient. These polyps are not always diagnosed with endoscopic biopsy because they are deeply localized [30]. Since our case could not be diagnosed with endoscopic biopsy, it was diagnosed with surgical enucleation.

A total of 64 patients (33.3\%) underwent polypectomy with snare. One patient had hemorrhage requiring endoscopic control. This patient's bleeding was controlled by endoscopic treatment. The low frequency of bleeding due to ESP may be treated by sclerotherapy, endoclip, or endoloop procedures. Mortality and perforation did not occur in any patient. Polypectomy with snare is a safe and effective method for the correct diagnosis and treatment of polyps.

As a result, the GP frequency in our study was very low $(0.34 \%)$. The most common type of gastric polyp was HP, but it must be kept in mind that GPs may have adenocarcinoma or precancerous histology, and removal of GP with appropriate technique (removal with biopsy forceps or polypectomy with snare) is recommended.

Conflict of Interest: No conflict of interest was declared by the authors.

Financial Disclosure: The authors declared that this study has received no financial support.

Authorship contributions: Concept - S.O.; Design - S.O., H.T.K., S.S.; Supervision - E.A.; Materials - S.O., S.S.,U.A., I.T., A.Y.S.; Data collection \&/or processing - A.Y.S., U.A, I.T.; Analysis and/or interpretation - S.O., B.S., E.O.; Writing - S.O., B.S.; Critical review - B.S., H.T.K.

\section{REFERENCES}

1. Goddard AF, Badreldin R, Pritchard DM, Walker MM, Warren B; British Society of Gastroenterology. The management of gastric polyps. Gut 2010;59:1270-6. [CrossRef]

2. Oberhuber G, Stolte M. Gastric polyps: an update of their pathology and biological significance. Virchows Arch 2000;437:581-90. [CrossRef] 
3. Carmack SW, Genta RM, Schuler CM, Saboorian MH. The current spectrum of gastric polyps: a 1-year national study of over 120,000 patients. Am J Gastroenterol 2009;104:1524-32. [CrossRef]

4. Morais DJ, Yamanaka A, Zeitune JM, Andreollo NA. Gastric polyps: a retrospective analysis of 26,000 digestive endoscopies. Arq Gastroenterol 2007;44:14-7. [CrossRef]

5. Makar GA, Ginsberg GG. Gastric Polyps. In: Faigel DO, Kochman ML, editors. Endoscopic Oncology. New Jersey: Humana Press; 2006. p. 109-20. [CrossRef]

6. Gencosmanoglu R, Sen-Oran E, Kurtkaya-Yapicier O, Avsar E, Sav A, Tozun N. Gastric polypoid lesions: analysis of 150 endoscopic polypectomy specimens from 91 patients. World J Gastroenterol 2003;9:2236-9.

7. Jalving M, Koornstra JJ, Wesseling J, Boezen HM, DE Jong S, Kleibeuker $\mathrm{JH}$. Increased risk of fundic gland polyps during long-term proton pump inhibitor therapy. Aliment Pharmacol Ther 2006;24:1341-8.

8. García-Alonso FJ, Martín-Mateos RM, González Martín JA, Foruny JR, Vázquez-Sequeiros E, Boixeda de Miquel D. Gastric polyps: analysis of endoscopic and histological features in our center. Rev Esp Enferm Dig 2011;103:416-20. [CrossRef]

9. Elhanafi S, Saadi M, Lou W, Mallawaarachchi I, Dwivedi A, Zuckerman M, et al. Gastric polyps: Association with Helicobacter pylori status and the pathology of the surrounding mucosa, a cross sectional study. World J Gastrointest Endosc 2015;7:995-1002. [CrossRef]

10. Macenlle García R, Bassante Flores LA, Fernández Seara J. Gastric epithelial polyps. A retrospective study 1995-2000. Rev Clin Esp 2003;203:368-72. [CrossRef]

11. Roseau G, Ducreux M, Molas G, Ponsot P, Amouyal P, Palazzo L, et al. Epithelial gastric polyps in a series of 13000 gastroscopies. Presse Med 1990;19:650-4.

12. Fan NN, Yang J, Sun G, Lu ZS, Ling Hu EQ, Wang XD, et al. Changes in the spectrum of gastric polyps in the Chinese population. World J Gastroenterol 2015;21:9758-64. [CrossRef]

13. Ozaydin N, Turkyilmaz SA, Cali S. Prevalence and risk factors of Helicobacter pylori in Turkey: a nationally-representative, cross-sectional, screening with the ${ }^{13} \mathrm{C}$-Urea breath test. BMC Public Health 2013;13:1215. [CrossRef]

14. Molaei M, Mashayekhi R, Zojaji H, Haghazali M, Zali MR. Gastric polypoid lesions: analysis of histopathologic features of 107 endoscopic polypectomy specimens. Gastroenterology and Hepatology From Bed to Bench 2008;1:127-32.

15. Karaman A, Deniz K, Karaman H, Gürsoy Ş, Başkol M, Güven K, et al. Prevalence and histopathological condition of gastric polyps in Central Anatolia. Endoskopi Dergisi 2011;2:56-8.
16. Buyukasik K, Sevinc MM, Gunduz UR, Ari A, Gurbulak B, Toros AB, et al. Upper gastrointestinal tract polyps: what do we know about them? Asian Pac J Cancer Prev 2015;16:2999-3001. [CrossRef]

17. Vatansever S, Akpınar Z, Alper E, İpek S, Yazıcıŏlu N, Ekinci N, et al. Gastric polyps and polypoid lesions: Retrospective analysis of 36650 endoscopic procedures in 29940 patients. Turk J Gastroenterol 2015;26:117-22. [CrossRef]

18. Demiryilmaz I, Albayrak Y, Yilmaz SP. Frequency of various types of gastric polyp. Cumhuriyet Med J 2011;33:209-14.

19. Graham JR. Gastric polyposis: onset during long-term therapy with omeprazole. Med J Aust 1992;157:287-8.

20. Stolte M, Sticht T, Eidt S, Ebert D, Finkenzeller G. Frequency, location, and age and sex distribution of various types of gastric polyp. Endoscopy 1994;26:659-65. [CrossRef]

21. el-Zimaity HM, Jackson FW, Graham DY. Fundic gland polyps developing during omeprazole therapy. Am J Gastroenterol 1997;92:1858-60.

22. Vieth M, Stolte M. Fundic gland polyps are not induced by proton pump inhibitor therapy. Am J Clin Pathol 2001;116:716-20. [CrossRef]

23. Choudhry U, Boyce HW Jr, Coppola D. Proton pump inhibitor-associated gastric polyps: a retrospective analysis of their frequency, and endoscopic, histologic, and ultrastructural characteristics. Am J Clin Pathol 1998;110:615-21. [CrossRef]

24. Hongo M, Fujimoto K; Gastric Polyps Study Group. Incidence and risk factor of fundic gland polyp and hyperplastic polyp in long-term proton pump inhibitor therapy: a prospective study in Japan. J Gastroenterol 2010;45:618-24. [CrossRef]

25. Yamamoto A, Ishiguro H, Kondo T, Naruse S, Goto H. Low prevalence of Helicobacter pylori infection in patients with fundic gland polyps. Nihon Rinsho 2005;63 Suppl 11:621-4.

26. Turner JR, Odze RD. Polyps of the Stomach. In: Odze R, Goldblum J. Surgical pathology of GI tract, Liver, Bilary tract and Pancreas. Saunders-Elsevier; p. 415-44. [CrossRef]

27. Stolte M. Clinical consequences of the endoscopic diagnosis of gastric polyps. Endoscopy 1995;27:32-7; discussion 59-60. [CrossRef]

28. Park DI, Rhee PL, Kim JE, Hyun JG, Kim YH, Son HJ, et al. Risk factors suggesting malignant transformation of gastric adenoma: univariate and multivariate analysis. Endoscopy 2001;33:501-6. [CrossRef]

29. Nam KW, Song KS, Lee HY, Lee BS, Seong JK, Kim SH, et al. Spectrum of final pathological diagnosis of gastric adenoma after endoscopic resection. World J Gastroenterol 2011;17:5177-83. [CrossRef]

30. Matsushita M, Hajiro K, Okazaki K, Takakuwa H. Endoscopic features of gastric inflammatory fibroid polyps. Am J Gastroenterol 1996;91:1595-8. 